\title{
GEOGRAFIA E PODER: CONFLITOS, RESISTÊNCIAS E CONTRA PODERES TERRITORIAIS
}

\author{
Geography and power: conflicts, resistances \\ and against territorial powers \\ Geografía y poder: conflictos, resistencias \\ y contra-poderes territoriales
}

\section{Márcia da Silva}

Doutora em Geografia pela Universidade Estadual Paulista Júlio de Mesquita Filho. Docente no Programa de Pós-graduação em Geografia da Universidade Estadual do Centro-Oeste (Unicentro). Universidade Estadual do Centro-Oeste (Unicentro), Campus Cedeteg, Departamento de Geografia, Rua Simeão C. Varela de Sá, n. 3, Vila Carli, 85040-080, Guarapuava/PR. E.mail:marcia.silvams@ gmail.com.

\section{Francisco Fransualdo Azevedo}

Doutor em Geografia pela Universidade Federal de Uberlândia. Docente no Programa de Pós-graduação em Geografia da Universidade Federal do Rio Grande do Norte (UFRN). Universidade Federal do Rio Grande do Norte, Centro de Ciências Humanas, Letras e Artes.

Departamento de Geografia, Campus Universitário. Av. Salgado Filho, 3000, Caixa Postal 1524, CEP 59.078-970 - Natal - RN. E.mail:ffazevedo@gmail.com.br

\section{RESUMO:}

Este texto é resultado do debate realizado no Grupo de Trabalho "Geografia e poder: conflitos e resistências/contra-poderes territoriais" realizado no XI Enanpege, em 2015, em Presidente Prudente, São Paulo. O grupofoi responsável pelo debate e socialização das reflexões sobre o processo de construção do conhecimento no âmbito da Geografia e sua vinculação às relações de poder, bem como às resistências territoriais e aos contra-poderes numa perspectiva multiescalar e de base local. Neste sentido, nos fundamentamos em experiências efetivadas pelos membros do grupo e por estudos elaborados por outros estudiosos brasileiros e estrangeiros, bem como pela aproximação no plano teórico e metodológico, destacando-se os sentidos políticos de cada concepção. A proposta do grupo de trabalho, então, buscou direcionar a pluralidade conceitual do poder na Geografia, o território, a territorialidade e as escalas territoriais nas interações espaciais. É neste sentido que os conflitos, os consensos e os agentes envolvidos asseguram a inter e a multiescalaridade pelas inovações (i) materiais que permitem a organização do espaço a partir ou não desuas resistências.

Palavras-chave: Poder, contra poderes, conflitos, resistências. 


\section{ABSTRACT:}

This text is the result from the debate performed in the Work Group "Geography and power: conflicts and resistances/against territorial rules" performed in Enanpege XI in 2015, in Presidente Prudente, São Paulo. The group was responsible for the debate and socialization of the reflections about the knowledge construction process in Geography area and its linking to the power relation, as well as territorial resistance and the againstpower in a multiscale perspective and local base. Thus, it was based on lived experiences by the members of the group and by studies done by other Brazilian and Foreigners scholars, as well the approach in theoretical and methodological plan, highlighting the political sense from each conception. The proposal of the work group, then, reached to a direction of conceptual plurality of power in Geography, the territory, territoriality and the territorial scales in special interactions. In this sense, the conflicts, the consensus and the individuals involved make sure the inter and multiscale by material innovations (i) that allow the organization of the space from or not their resistances

Keywords: Power, against powers, conflict, resistance.

\section{RESUMEN:}

Este texto resulta de las discusiones del Grupo de Trabajo "La geografía y el poder: conflicto y resistencia/contra-poderes territoriales", presentado en el XI ENANPEGE -2015, en la ciudad de Presidente Prudente, São Paulo. El grupo de trabajo fue responsable por la discusión y socialización de reflexiones sobre el proceso de construcción del conocimiento geográfico y su vinculación con las relaciones de poder, con las resistencias territoriales y con los contra-poderes en una perspectiva de múltiples escalas y la base local. En este sentido, fue fundamental la experiencia de los miembros del grupo a través de sus estudios y de otros estudiosos brasileños y extranjeros, así como el enfoque en el nivel teórico y metodológico destacando los significados políticos de cada concepción. La propuesta del grupo de trabajo, por tanto, trató de dirigir la discusión a la pluralidad conceptual sobre el poder en la geografía, el territorio, la territorialidad y las escalas territoriales en las interacciones espaciales. Por lo tanto, los conflictos, el consenso y los participantes intentaron asegurarse de una discusión sobre múltiples escalas y relaciones inter escalares por las innovaciones materiales que permiten a la organización del espacio basada en la resistencia o no.

Palabras clave:Poder, contra poderes, conflictos, resistências. 


\section{O PODERE OS CONTRA PODERES DOS GRUPOS SOCIAIS NA CONSTRUÇÃO DE TERRITÓRIOS}

A temática poder e seus derivados fazem parte de debates recentes, em termos de estrutura específica das análises, vinculados à ciência geográfica. Os pesquisadores do tema estão quase sempre estabelecidos em áreas como a Ciência Política, a História, a Sociologia, a Administração. Na Geografia, despertou maior interesse a partir da obra "Por uma Geografia do poder”, de Claude Raffestin (1993), na qual o conceito é abordado como uma “[...] 'novidade' no quadro de sua disciplina, quase sempre rebelde à introdução de noções que não são objeto de uma tradução espacial imediata” (RAFFESTIN, 1993, p. 5).

No entanto, o que se percebe ao longo da formação e do desenvolvimento da ciência geográfica, é que o uso do conceito de poder não foi negligenciado, estando presente nas discussões sobre a organização política, mais expressivamente nas análises sobre o Estado e suas instituições.

Destaca-se, assim, a afirmação de Raffestin (1993) de que “[...] conhecer e operar sobre uma realidade material supõe - e até mesmo postula - um sistema de relações no interior do qual circula o poder, uma vez que este é consubstancial à toda relação" (RAFFESTIN, 1993, p. 6). Diante disso, o poder passa a ser também objeto de estudos na Geografia, uma vez que imbricado nas relações sociais e não somente na estrutura do Estado.

Mesmo com o além Estado, instituições, sentencialismos, as relações de poder são intencionais, por isso, não são neutras de subjetividades, sendo construídas por meio de valores, crenças, símbolos, entre outros elementos socialmente vividos.

Por meio desses elementos, rompe-se com a visão unilateral que, por muito tempo, configurou-se na história da humanidade e na ciência, a de que o poder tem existência por si só, sendo algo natural, um mito da visão unilateral de que o poder é algo material e/ou mercadológico, algo que se possa trocar, comprar, adquirir. Essa perspectiva contrapõe-se aquela de o poder é, mais que isso, exercido por atores e/ou grupos na relação com o outro, ou seja, é a relação instituída entre atores e/ou grupos no espaço e no tempo.

Dado o exposto, a sustentação reflexiva do estado da arte em termos de poder está amparada na observação da atuação de diferentes grupos na construção relacional e como essas relações estão imbuídas na abstração do interesse e envolvimento entre diferentes atores sob a construção do território. Por conseguinte, afirma-se que o poder é exercido e, consequentemente, resistido e/ou aceito, mas para isso é necessário que os atores e/ou grupos que o exerçam tenham conhecimento de sua lógica e intencionalidade sobre a ação. Todavia, o poder é estabelecido na mediação entre o conflito de interesses de atores e/ou gruposuns com os outros. 
Em complemento a esta análise, Nobre et al (2008), na obra "O poder no pensamento social" considera que os estudos até então publicados sobre poder são interdisciplinares, pois, independentemente da área de concentração, se sociológica, política, antropológica, histórica ou geográfica é possível encontrar discussões "[...] às voltas com o tema do “poder”, uma vez que haverá amiúde a possibilidade de se verificar a presença de exercícios de poderes no âmbito dos mais variados tipos de relações" (NOBRE et al, 2008, p. 11).

Para Perissinotto (2008, p. 26) “[...] poder constitui-se num dos mais controversos conceitos das ciências sociais". O autor destaca três grandes dificuldades que os pesquisadores encontram ao estudar o tema:

[...] primeira, a multiplicidade de definições, em geral, apresentadas como excludentes sem que o sejam de fato; segundo, os problemas de operacionalização das definições, sendo algumas delas muito precisas, mas muito superficiais, e outras mais sofisticadas porém de difícil aplicação empírica; por fim, a justaposição de definições, que que alguns utilizam palavras diferentes para designar os mesmos fenômenos ou lançam mão dos mesmos termos para designar relações sociais distintas (PERISSINOTTO, 2008, p. 29).

Ao interpretar esses três pontos elencados por Perissinotto (2008), pode-se dizer que no primeiro item temos duas explicações, uma que soa de forma positiva, visto que a multiplicidade não é sinônimo de fracasso epistemológico, mas sim esta característica apresenta-nos a multiplicidade dos "olhares" acadêmicos. Contudo, é necessário ressaltar que uma concepção não supera a outra, isto é, quando o autor considera que em alguns casos o estudo sobre poder exclui outra percepção, ele está apontando para o fato de que uma visão está negando a outra.

A segunda proposição destacada por Perissinotto (2008) está em relação à operacionalização das definições, visto que o autor lança uma discussão acerca da qualidade e aplicabilidade do conceito de poder aos objetos de pesquisas.

Na terceira consideração do autor está a dificuldade ao tratar o tema poder, sendo que, por vezes, só há a utilização da palavra em sentido diferente para o que academicamente está elaborado, ou ainda, em equívoco, utilizam-se bases teóricas para objetos totalmente distintos do analisado pelas teorias.

Dadas essas três abordagens, a intenção aqui, como resultado do Grupo de Trabalho, é contribuir com os múltiplos "olhares" sobre o tema, sem negar as concepções construídas sobre outros vieses sobre o conceito de poder. Dentre elas, podemos citar reflexões de Robert Dahl e Claude Raffestin. O destaque dado a esses três autores é de suma importância para os estudos da Geografia do Poder, tendo em vista que suas reflexões estão pautadas nas relações sociais centralizadas sob o olhar nas transformações que as relações de poder 
concretizam no território. Especificamente, neste trabalho, Robert Dahl e Claude Raffestin representam parte da evolução epistemológica do conceito de poder.

Dahl, que recebeu influência de Floyd Hunter, Wright Mills e Peter Bacharach, dedicou parte de sua vida acadêmica aos estudos sobre o poder contribuindo significativamente para a temática ao alçar o questionamento sobre "O que é poder?” Ao fazer esta indagação, na introdução do seu trabalho intitulado, "The concepto of power", publicado em 1957, traz à tona a complexidade do conceito. Para o referido autor, o conceito de poder é ambíguo, tendo por fundamento cientistas sociais que se atentaram a desvendar o poder e os fenômenos a este associados, como Nicolau Machiavel, Thomas Hobbes, Vilfredo Pareto, Max Weber, dentre muitos outros:

Because of this, the concept of power is as ancient and ubiquitous as any that social theory can boast. If these assertions needed any documentation, one could set up anendless parade of great names from Plato and Aristotle through Machiavelli and Hobbes to Pareto and Weber to demonstrate that a large number of seminal social Theorists have devoted a good deal of attention to power and the phenomena sociated with it (DAHL, 1957, p. 201).

Para Robert Dahl, ao longo dos aportes desenvolvidosno aprofundamento teórico de suas obras, é necessário observar a singularidade existente nas relações de poder com outras relações que resultam em conceitos significativamente prioritários aos estudos sobre poder, em diferentes idiomas e interpretações. Em relação as singularidades com os conceitos de influência, controle, potência e autoridade, Dahl (1957, p. 201) afirma que:

Doubtless it would be easy to show, too, how the word and its synonyms are evcrywhere embedded in the languagc of civilized peoples, often in subtly different ways: power, influence, control, pouvoir, puissance, Macht, Herrschaft, Gewalt, imperium, potestas, auctoritas, potentia.

Para Bobbio (1987), o conceito de poder pode ser considerado conforme as abordagens de Dahl, ou seja, na relação em que os atores estabelecem na mediação da indução, sendo um ator induzido por outro a atuar socialmente de forma anteriormente não atuada. Assim sendo, o poder é constituído na mediação relacional entre o ator dominado e o ator dominador, ao ponto de esta estruturar determinados grupos.

Sob essa lógica organizacional do conceito de poder, Dahl aponta que "my intuitive idea of power, then, is something like this: a has power, over $B$ to the extent that he can get $B$ to do something that B would not otherwise do" (DAHL, 1957, p. 202). A definição exposta permite compreender que o poder é exercido numa relação desigual sendo um o dominador e o outro o dominado. A esse respeito, pode-se concluir que a relação de poder entre um ator e outro é assimétrica, isto é, um está em oposição ao outro, mas numa mesma relação.

No momento em que os interesses se encontram, o próprio movimento contrário da 
ação leva-o a conflitar, isto é, há um choque de interesses, fazendo com que o exercício do poder resulte significativamente no grau de confluência entre influência/controle/potência/ autoridade da ação do poder exercitada de $A$ sobre $B$.

Sánches (1981) aborda, em sua obra "La Geografia y el espacio social del poder", considerações sobre a centralidade analítica imbuída nas reflexões do espaço como produto social, mais expressivamente sobre a observação do próprio homem, conforme destaque:

Es el hombre em <la producción real de su existência $>$ el que me interessa por sí mismo y también por cuanto a través de esta 'producción' convierte el espacio geográfico em umespacio social a lo largo lucha de dos elementos - el hombre y el espacio - com el tempo como espactador de la historia (SANCHÉZ, 1981, p. 9).

Essa fundamentação permite-nos afirmar que, a priori de qualquer relação de poder, há o compromisso de repensar a própria necessidade construída pelos homens em sociedade, sendo "el espacio es el campo de la realidade sobre el que trabajan los geógrafos. Este espacio engloba todas las relaciones sociales y humanas, y todos los hechos físicos que se hallan a nuestro alcance están contenidos em él” (SANCHÉZ, 1981, p. 21).

Nesse sentido, o autor parte da hipótese de que a articulação do espaço social não é um resultado nem aleatório nem determinista. Para o pesquisador, o que existe é uma interdependência entre o meio físico como necessidade, atuação e estrutura do poder e, consequentemente, os interesses territorializados constituem-se "el espacio social del poder" (SANCHÉZ, 1981). Sendo assim, objetivado na investigação em:

[...] buscar las relaciones que existen enun área en particular de la realidade, el espacio, a fin de ver caules son las regularidades que lo infoman, las variables que interviene y el ligamen y la dependecia que existe entre ellas, sea éste nulo, mutuo, dominante o subordinado (SANCHÉZ, 1981, p. 14).

Essa reflexão permite-nos realizar algumas ponderações para a análise do objeto em questão. Ao entender que o espaço geográfico, objeto de estudo dos geógrafos, é constituído por relações sociais, podemos afirmar que as relações sociais são estabelecidas mediante a necessidade de cada período histórico, como destacado no parágrafo anterior. No entanto, essas necessidades estão vinculadas aos interesses de cada grupo em períodos históricos distintos.

Sendo assim, apresentam-se três eixos de discussão central na análise sobre o poder, conflitos, resistências e contra poderes territoriais: o espaço geográfico essencialmente social; o tempo histórico como requisito de representatividade das necessidades sociais e; as próprias necessidades dados os interesses de cada grupo de poder. 
Barracho (2008) apresenta, em sua análise, várias definições de poder, das clássicas as mais contemporâneas. No entanto, destaca que cada definição foi estruturada mediante o objeto e o método de pesquisa utilizado e, para o autor, as interpretações estão amparadas em diferentes abordagens, considerando centralidade nas visões de cunho social, econômico, político e filosófico.

Nesse sentido, Barracho (2008) contextualiza a origem da discussão acadêmica sobre o conceito de poder atrelado aos movimentos paradigmáticos das ciências.

\begin{abstract}
A Economia, devido ao seu interesse pelas questões da pobreza e da riqueza dos povos e das nações, debateu também as questões do poder. No século XX, devido ao desenvolvimento do estudo das relações interpessoais, estendeu-se ao domínio da Psicologia, em particular da Psicologia Social e das Organizações. Para a Ciência Política, tornou-se um conceitochave, a compreensão, interpretação e categorização dos estudos sobre o poder, nos mais diversos níveis societais, em particular dos grupos políticos, das relações internacionais e da geo-política. Construíram-se, assim, teorias e modelos explicativos deste fenómeno, com a finalidade de se encontrarem denominadores comuns e metodologias práticas, estabelecendose abordagens científicas, cujo rigor, permitiu constituir e desenvolver uma nova disciplina académica (BARRACHO, 2007, p. XI).
\end{abstract}

Sanchéz (1981) considera que, em sentido amplo, Marx Weber associa o conceito de poder com o de obediência. Para este autor, existem várias instâncias de atuação do poder, no entanto, ao estudá-las é necessário observar os critérios de interesses de atuação de cada ator ou grupo. Neste sentido, para o autor, essa visão weberiana presume compreender que a obediência existe na relação de um ator em relação ao outro, no entanto, é necessário haver força e aceitação.

Assim, o poder só existe na relação, por isso se não há envolvimento do entre atores ou grupos é porque não há relação e, consequentemente, não há poder. Todavia, no momento em que o grupo 1 inicia o contato com o grupo 2 (sem adentrar as intenções e as finalidades que estes tiveram ao se relacionar), a forma operacional como estes se relacionam é condicionada ao exercício da força e da aceitação. Sendo assim, um grupo de poder só atua quando há relações ou possibilidades de exercício da força e, dessa forma, territorializar o poder.

Sob essa mesma lógica, Raffestin (1993, p. 53) realiza a seguinte afirmação:

O poder se manifesta por ocasião da relação. É um processo de troca ou de comunicação quando, na relação que se estabelece, os dois pólos fazem face um ao outro ou se confrontam. As forças de que dispõem os dois parceiros (caso mais simples) criam um campo: o campo do poder. Para compreender isso, pode-se recorrer à imagem do ímã e dos fragmentos de limalha que se orientam e assinalam linhas de força. O campo da relação é um campo de poder que organiza os elementos e as configurações. 
Ao considerar os grupos de poder analisa-se que estes são formados por atores que se articulam por diferentes interesses, num grau de dependência relacional com o período histórico vivido, resultado do exercício do poder na relação estabelecida com o outro. Para Sanchéz (1981) a origem do poder está vinculada à prática social que determina o seu exercício em diferentes escalas, dos micro aos macro poderes, com atuação de instituições como a família, os meios de comunicação, a sociedade civil organizada, a justiça e outras.

Tanto a gênese quanto o exercício do poder são estruturados mediante as intensões e finalidades de atuação dos atores e grupos por meio de suas estratégias de dominação. Nesse mesmo sentido Raffestin (1993) considera o poder relacional, colaborando com Sanchéz ao discorrer sobre as dificuldades dos estudos sobre a abordagem relacional. Dessa forma, podemos entender que os enigmas da relação social estão justamente na sobreposição do entendimento da estrutura social.

Para Raffestin (1993, p. 38), os elementos constitutivos da relação são “[...] os atores, a política dos atores - ou o conjunto de suas intenções, isto é, suas finalidades -, a estratégia deles para chegar a seus fins, os mediatos da relação, os diversos códigos utilizados e os componentes espaciais e temporais da relação". "Enquanto o poder faz parte de todo o processo relacional".

Raffestin (1993), fundamentado em Foucault (1976), ao tratar da origem do poder, utiliza-se de cinco proposições consideradas esclarecedoras do debate aqui apresentado:

1. O poder não se adquire; é exercido a partir de inumeráveis pontos;2. As relações de poder não estão em posição de exterioridade no que diz respeito a outros tipos de relações (econômicas, sociais etc.), mas são imanentes a elas;3. O poder vem de baixo; não há uma oposição binária e global entre dominador e dominados;4. As relações de poder são, concomitantemente, intencionais e não subjetivas;5. Onde há poder há resistência e, no entanto, ou por isso mesmo, esta jamais está em posição de exterioridade em relação ao poder (RAFFESTIN, 1993, p. 53).

Essas cinco proposições destacadas são defendidas por Raffestin (1993) ao longo de todas as suas obras, isso porque o autor considera que a atuação de atores sintagmáticos é estrategicamente pensada e a ação depende do projeto inicial à tomada das intencionalidades e finalidades.

Sendo assim, levanta-se uma problemática de ordem teórica no sentido de que, se estamos falando de disputas realizadas no estabelecimento do poder entre grupos, temos que considerar o trunfo que o poder pode gerar, isto é, o que a relação estabelecida na disputa ou concordância pode ter como consequência. Desse modo, internamente, os interesses ideológicos, políticos e econômicos são marcados por poderes estabelecidos entre os grupos, mas o jogo que permanece entre as disputas dos dominados e dominadores está presente na relação e, não necessariamente, na origem do poder. 
Assim, na contemporaneidade é impossível estudar as relações de poder sem compreender a forma como a sociedade está organizada, posto que os trunfos do poder, em alguns momentos, são identificados por grupos de poder como mercadoria, isso é, tem valor de mercado perante as negociações. Com isso, é possível afirmar que o poder pode ter sua origem na própria satisfação do que é construído no imaginário do grupo, no entanto, os trunfos são controlados à medida que prevalece o poder de um grupo em detrimento de outro.

Para compreendermos como o conceito de poder e suas formas têm sido trabalhados na Geografia, via seus conflitos, resistências e contra poderes, apresentamos, na sequência, alguns aspectos das contribuições ao Grupo de Trabalho reunido no Enanpege de 2015, em Presidente Prudente/SP.

\section{GRUPO DE TRABALHO GEOGRAFIA E PODER: VÍNCULOS DOS AUTORES E RECORTES DE ANÁLISE}

O GT Geografia e Poder contou com a presença de pesquisadores de quatro das regiões do Brasil, Sudeste, Sul, Centro-Oeste e Nordeste, com destaque para os estados do Paraná e de São Paulo. A figura 1 apresenta o número de trabalhos aprovados no grupo Geografia e Poder, com os respectivos vínculos dos autores no que diz respeito à unidade federativa de origem e vínculo institucional.

Figura 1: Grupo de Trabalho Geografia e Poder -Vínculos dos autores (estado e instituição) dos trabalhos

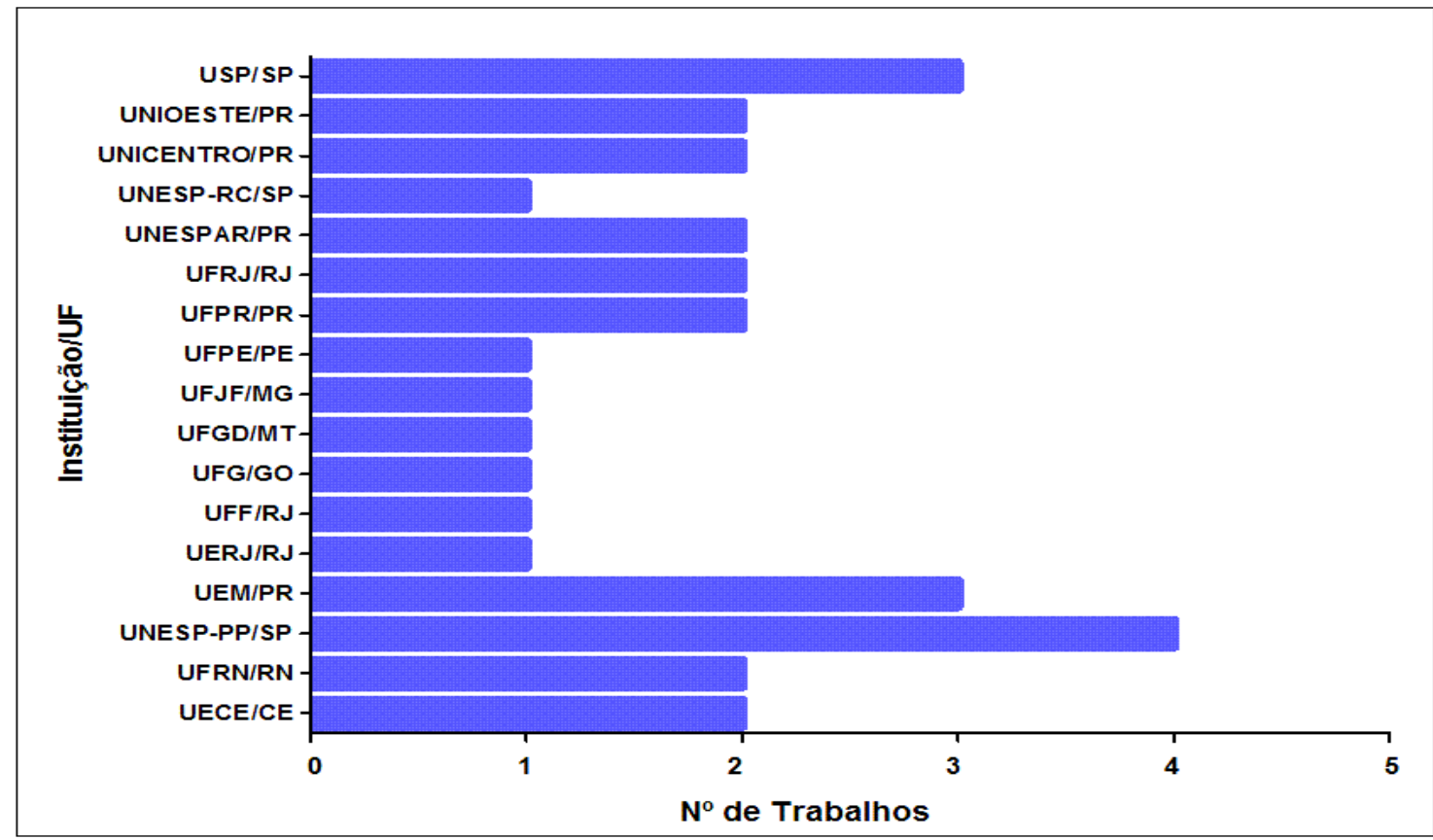

Fonte: XI ENANPEGE - Grupo de Trabalho Geografia e Poder.

Org.: Teixeira, Vanessa (2016). 
Pode-se perceber, pela figura 1, participação linear de pesquisadores de diferentes universidades, mas sem maiores discrepâncias em número de trabalhos, ou seja, as universidades participantes enviaram entre 1 e 4 trabalhos, sendo destaques a UNESP-PP, com 4 trabalhos e UEM e USP com 3 trabalhos cada.

Em termos de origem das pesquisas apresentadas, estas estavam vinculadas às teses e dissertações orientadas pelos coordenadores do grupo, contudo, houve participação e abertura para divulgação e debates de pesquisas externas aos grupos de pesquisas dos professores coordenadores do GT.

Sendo o recorte de análise e a escala de análise preocupações recorrentes nos estudos da ciência geográfica, ostrabalhos apresentados no grupo Geografia e Poder tinham vinculações com diversas delas na perspectiva de diagnosticar o território. Segundo Zacharias (2006, p. 45):

A escala dos fenômenos que se dão no espaço é geográfica, embora sua representação seja feita por meio da cartográfica. Em determinadas escalas (geográficas maiores) alguns fatores não aparecem, ou mesmo são visíveis. Neste caso, se faz necessário mudar de escala, o que repercute na perda da visão de alguns destes fatores/agentes.

Para tanto, o enfoque do recorte e da escala são primordiais para a compreensão dos fenômenos vinculados ao território. Há, assim, necessidade de utilizar um ou mais recortes de análise, buscar compreender os fenômenos a partir de trocas escalares, consubstanciando diferentes recortes que possibilitem uma análise mais ampla do tema pesquisado. Em grande maioria, os trabalhos apresentados balizaram-se pelo recorte territorial local/regional, como é possível observarna figura 2. 
Figura 2: Grupo de Trabalho Geografia e Poder - Recorte de análise/escala dos trabalhos

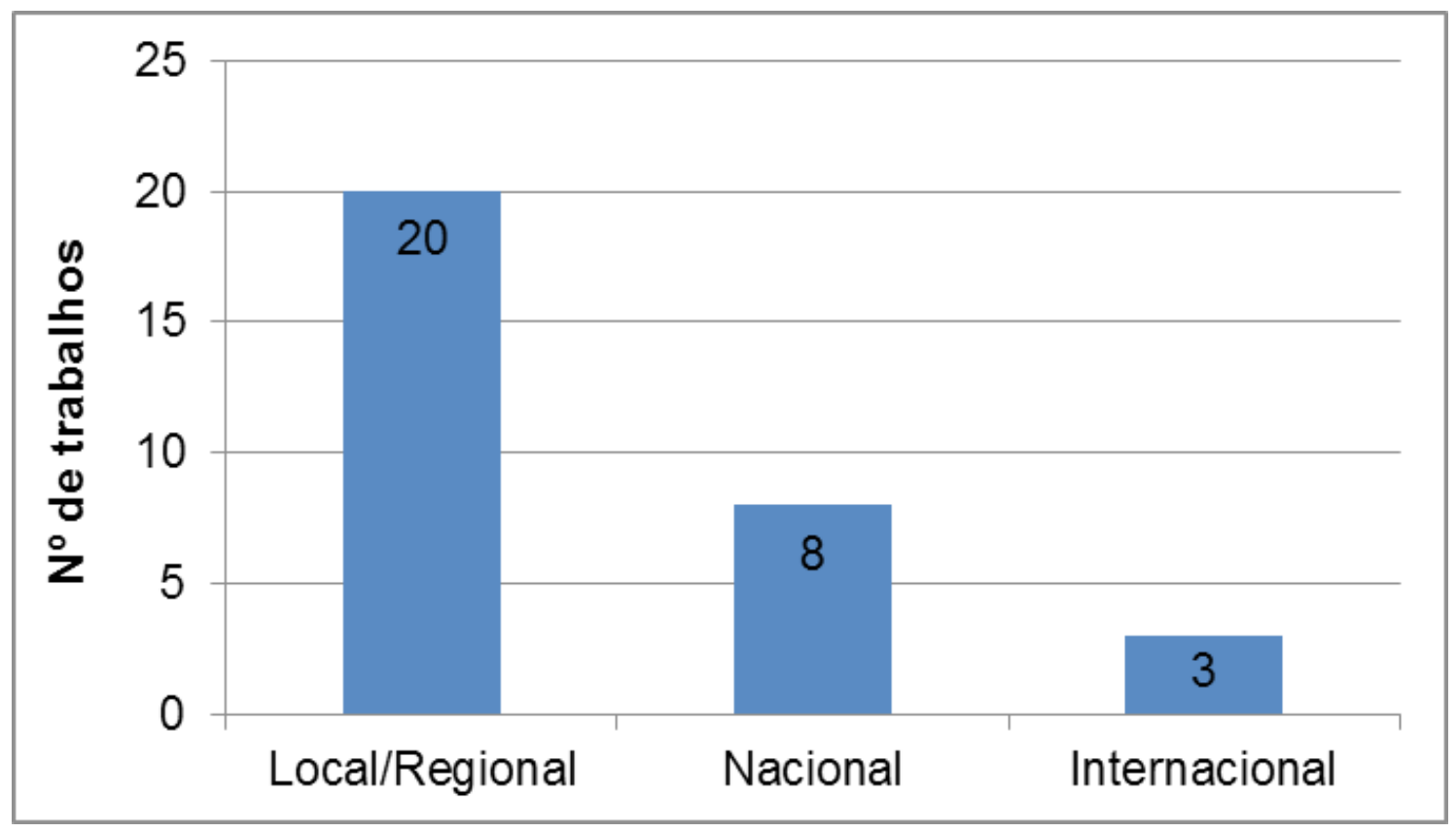

Fonte: XI ENANPEGE - Grupo de Trabalho Geografia e Poder.

Org.: Teixeira, Vanessa (2016).

É possível observar, pelo gráfico 2, que o recorte utilizado para as temáticas das pesquisas apresentadas no grupo Geografia e Poder foram o "local/regional". Do total de trabalhos, 20 tiveram como enfoque estas escalas. Na sequênciaestá, em número bem reduzido, aqueles que buscaram analisar o poder e o território em uma escala mais ampla, o "nacional" (oito) e, em seguida, o "internacional" (três), vinculado a perspectivas que analisaram elementos para além do contexto brasileiro.

Neste sentido, foi motivo de debate no acontecer do GT, os motivos os quais a Geografia brasileira pauta-se (na grande maioria) em estudos de caso, que basicamente se concretizam nas análises do local e regional. Uma dentre as várias possibilidades aventadas está na dificuldade de realização de trabalhos de campo recorte brasileiro ou, também, pela própria facilidade que há no desvendar das escalas local/regional, que permitem ao pesquisador maior domínio da realidade, bem como maior rapidez e eficiência.

Estas possíveis motivações devem ser encaradas como algo a ser repensado pela ciência geográfica brasileira, pois há necessidade de conhecer e abordar outras realidades, o que poderá possibilitar uma internacionalização dastemáticas de pesquisa, via comparação aos estudos e produções sobre o território brasileiro, inclusive com financiamentos das agências de fomento. 


\section{OS PRINCIPAIS CONCEITOS/TEMAS PRESENTES NOS TRABALHOS}

Em análise e avaliação (figura 3) do uso de alguns conceitos-chave/temasnos 31 trabalhos publicados no eixo Geografia e Poder pode-se observar a presença daqueles que fundamentam a Geografia Política, como Território (31), Estado (27), poder (22), política (21), conflito (18), ideologia (17). Os conceitos/temas políticas públicas (10), poder político (9), fronteira (8), poder local (6), democracia (6) e geopolítica (5) aparecem na sequência com significativa presença nos trabalhos publicados, ainda que, na maioria deles possam ser identificados mais de um conceito/tema.

O estabelecimento de conceitos/temas se insere como elemento fundamental para a compreensãodos aspectos temáticos priorizados pelos autores participantes do GT e que compõem o conjunto de trabalhos publicados. O posicionamento teórico assumido pela utilização ou não dos diferentes tipos de abordagem torna-se representativo daquilo que a subárea tem produzido ou as possíveis demandas futuras.

Figura 3: Grupo de Trabalho Geografia e Poder - Principais conceitos/temas presentes nos trabalhos

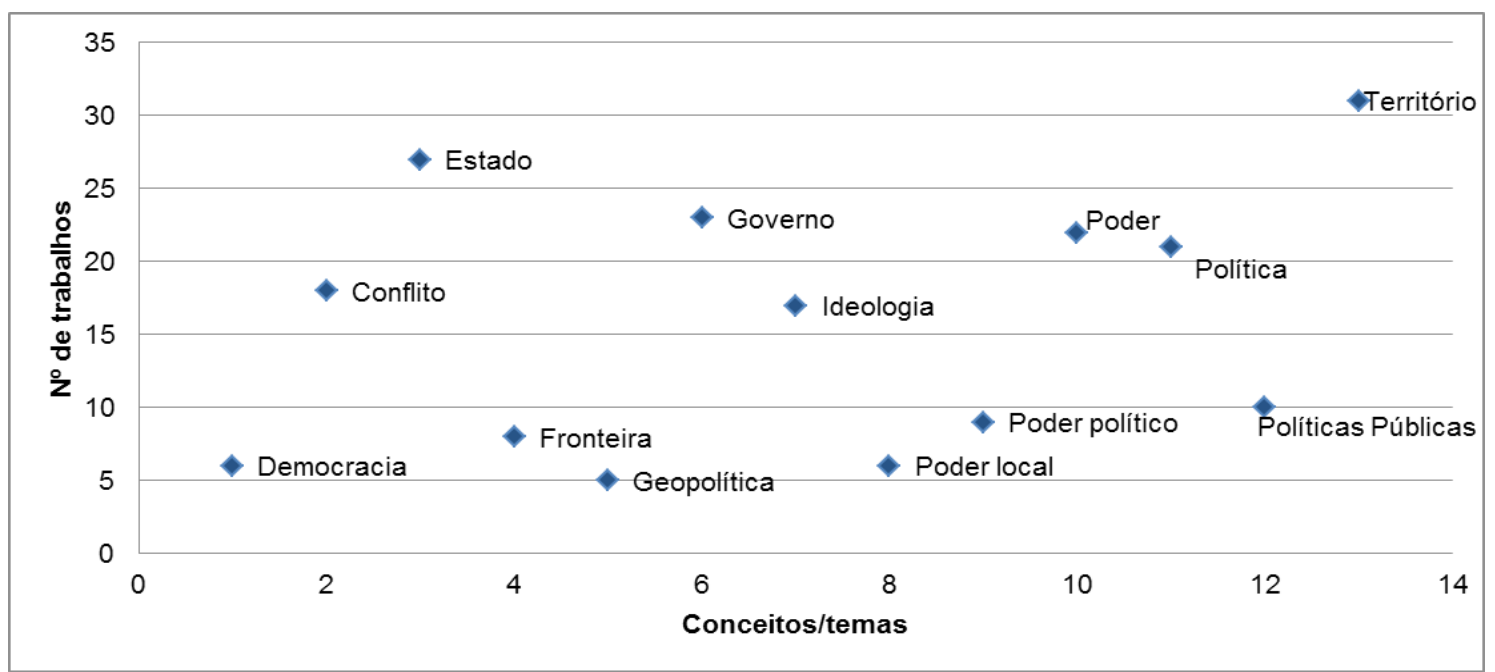

Fonte: XI ENANPEGE - Grupo de Trabalho Geografia e Poder.

Org.: TEIXEIRA, Vanessa (2016).

A figura 3 demostraque a produção científica do grupo de trabalho Geografia e Poder está densamenterelacionada aos conceitos/temas que integram problemáticasde significativa importância para a Geografia e que compreendem a atuação dos mais diversos agentes, em diferentes perspectivas escalares,nas relações de poder e resistência, domínio e controle territorial.

Em vinculação conceitos/temas tratados e autores mais utilizados nos textos enviados ao GT Geografia e Poder, verifica-se fundamentação variada, mas de maior relevância 
de clássicos contemporâneos como Jean Gottmann, Claude Raffestin, David Harvey, Guy Debord,Michael Foucault, Enrique Leff, Luis Razeto, Henri Lefebvre, Chris Anshell, Fréderic Douzet, Boris Beaude e outros. É assim que a análise da dimensão espacial do poder tem representatividade ao se observar a organização política do território como elemento preponderante nos trabalhos enviados ao GT Geografia e Poder, dos quais fazse uma análise na sequência.

\section{CONCEITOS E TEMAS SOBRE GEOGRAFIA E PODER, CONFLITOS, RESISTÊNCIAS E CONTRA-PODERES TERRITORIAIS}

Tendo em vista que nessa perspectiva de discussões sobre relações de poder a existência de conflitos territoriais se constitui como um elemento definidor dos vários usos do território e das resistências territoriais, debateu-se também os contra-poderes numa perspectiva multiescalar, do local ao global, do regional ao nacional, a exemplo de questões que dizem respeito aos lugares, tais como conflitos territoriais referentes ao uso agrícola do solo ou ligados às resistências camponesas e/ou indígenas como o caso de Dourados (MS), Campo Mourão no Paraná ou contra-poderes relacionados ao papel dos sujeitos e atores do movimento da economia solidária na Colômbia.

O Grupo de Trabalho possibilitou discussões teóricas que envolvem desde o resgate das diferentes abordagens feitas em eventos científicos na linha de investigação da Geografia Política, em nível de pós-graduação, em especial no ENANPEGE, além de resgatar enfoques clássicos e contemporâneos sobre território e poder, resistência territorial, contra-poderes e relações contra-hegemônicas no contexto da sociedade atual. Foram tratados temas ligados à Geografia eleitoral, a exemplo da questão do voto e relações de poder implícitas, poder das elites locais na configuração do território, redes de poder e produção do território em assentamentos rurais.

Como sendo de fundamental importância no contexto de discussões da Geografia Política, e mesmo que polissêmico, o temário sobre desenvolvimento fez parte das discussões revisitando-se literatura clássica como Celso Furtado e Ignacy Sachs, especialmente no tocante ao desenvolvimento local e regional, desenvolvimento sustentável e suas contradições. Problematizou-se o desenvolvimento sustentável do ponto de vista conceitual, mas questionando-se como este vem sendo defendido e a quem interessa tal abordagem, sinalizando-se para as distorções e contradições que permeiam tal debate, a partir de uma lógica nem sempre coerente e concatenada com a justiça social e o equilíbrio ambiental face ao poder econômico dos agentes hegemônicos do capital. 
Outro tema de fundamental importância quando se discute política e poder na ciência geográfica diz respeito ao papel do Estado na implementação de políticas públicas no território, as diferentes racionalidades, os diferentes agentes e interesses envolvidos no ambiente estatal e no próprio desenvolvimento das políticas públicas, sejam elas de caráter social ou não. Observa-se que o Estado define muitas vezes suas estratégias de ações a partir dos anseios da sociedade, apesar de nem sempre prevalecer os interesses coletivos e de indivíduos e grupos não-hegemônicos, mas interesses muitas vezes das classes mais abastadas da sociedade e dos agentes hegemônicos no território, a exemplo, dos interesses de mineradoras, grandes indústrias, construtoras, bancos, empresas do setor comercial e de serviços.

Diante disso, merece destaque alguns detalhamentos das discussões feitas em torno do tema em tela com base nos trabalhos apresentados:

A decisão do voto em diferentes escalas de pleitos eleitorais: exemplos de Portugal

O trabalho buscou apresentar algumas considerações acerca da decisão do voto em diferentes escalas de pleitos eleitorais. Utiliza-se como elemento norteador a democracia e o voto em Portugal. Três foram as cidades escolhidas para a recolha das amostras da pesquisa de campo: Braga, Évora e Lisboa. Destaca-se a diferenciação dos níveis de identificação pessoal e identificação partidária no eleitorado, a qual se modificou de acordo com a escala do pleito eleitoral.

A geografia política brasileira contemporânea a partir dos anais do ENANPEGE: interesses, abordagens e uma agenda

Discute-se a Geografia Política brasileira contemporânea a partir da disseminação de pesquisas nessa área, tendo como fonte trabalhos completos apresentados no Encontro Nacional da Associação Nacional de Pesquisa e PósGraduação (ENANPEGE) pelo seu uso conceitual. Assim, foram apresentadas as discussões realizadas até o presente momento, reportando-se aos dados do VIII ENANPEGE realizados no ano de 2009; IX ENANPEGE realizado no ano de 2011 e; X ENANPEGE realizado no ano de 2013.

A territorialização dos grupos de poder na criação do Parque Estadual das Várzeas do Rio Ivinhema-MS-Brasil

O estudo volta-se para a problemática do Parque Estadual das Várzeas do Rio Ivinhema/PEVRI, localizado em Mato Grosso do Sul que foi configurado por relações de poder e interesses externos ao local, que ao ser criado territorializam-se relações políticas, ideológicas e econômicas anteriormente inexistentes ao local. 
As elites locais e a organização do território

Buscou-se problematizar a relação entre as elites locais e o processo de organização do território no Norte-Fluminense, mais especificamente em Campos dos Goytacazes. Foram trabalhados os conceitos de território e elites, esboçando algumas discussões acerca dos mesmos, além da análise da organização do território campista, situando os momentos na formação da elite, ligados à cana de açúcar, e que dominou o território ao longo da história, tratando ainda o período atual da crise da tradicional elite usineira, e do surgimento de uma elite política baseada na administração pública, e nos vultosos recursos das rendas petrolíferas.

As práticas de inovação social na economia solidária: expressões territoriais num âmbito de relação urbano-rural na sub-região II do Departamento de Risaralda-Colômbia

O trabalho propõe estabelecer uma matriz discursiva teórica num primeiro momento - apresentando as práticas de inovação social como esquemas de diferenciação criativa legitimados socialmente, e que, sustentando as inovações sociais sobre a economia solidária. A argumentação percorre três estudos de caso como diferentes expressões territoriais, necessárias para pensar num campo relacional e processual com objetivos interdisciplinares.

As redes de poderes e a produção do território em assentamentos rurais no sudeste de Goiás

O trabalho visa compreender as redes de poderes e a produção do território em assentamentos rurais no Sudeste Goiano, abrangendo os municípios de Goiandira (Assentamento Madre Cristina), Ipameri (Assentamento Olga Benário) e Orizona (Assentamento Maria da Conceição). Os eixos de relações de poderes discutidos foram: a conquista da terra, as relações (i)materiais com a cidade/mercados/agronegócio, as relações com as governamentalidades e as redes religiosas.

As territorialidades dos grupos de poder político em Ivaiporã/PR

O estudo identifica os principais grupos políticos de Ivaiporã/PR e suas territorialidades. Dessa forma, foram identificados três principais grupos políticos em Ivaiporã e seus respectivos vínculos políticos, o Partido dos Trabalhadores (PT), o Grupo Papin e o Grupo do Partido do Movimento Democrático Brasileiro (PMDB).

As tessituras do poder no território Manaus e entorno/AM

O trabalho constata que o município de Manaus e entorno surge a partir da Política de Desenvolvimento Territorial Sustentável iniciada em 2003. A abordagem territorial é a 
principal estratégia, pautado em múltiplas dimensões: econômica, sociocultural, políticoinstitucional e ambiental. Criando para a discussão da política a arena do Colegiado de Desenvolvimento Territorial - CODETER, que seria o espaço de diálogo entre sociedade civil e poder público para articulação e discussão de projetos a serem implantados no território.

Circuito espacial de produção têxtil e uso do território nos municípios de Caicó e Jardim de Piranhas - região do Seridó Potiguar

O trabalho analisa o uso do território pelo circuito espacial de produção têxtil nos municípios de Caicó e Jardim de Piranhas, região do Seridó Potiguar, buscando problematizar como se configuram resistências territoriais, levando em consideração que esses agentes constituem uma contra-racionalidade ao processo de globalização do capital.

Conflito territorial no quilombo Mesquita localizado entre Cidade Ocidental (GO) e o Distrito Federal (DF)

A análise destaca que o quilombo Mesquitatem recebido as consequências da polarização da capital federal que expande para dentro do quilombo sua demanda por loteamentos habitacionais. A possibilidade de promoção de um mercado habitacional para a classe média de Brasília nos últimos tempos tem promovido a especulação imobiliária ainda mais intensa, tanto dentro, quanto nas proximidades do Mesquita. Mas a presença de um território quilombola, que não busca uma exploração fundiária exclusivamente voltada para ganhos financeiros, tem sido considerado um bloqueio ao desenvolvimento econômico local, o que induziu a formação de um conflito territorial ambiental no território de 4.292,93 hectares ocupados por 755 famílias.

Conflitos socioambientais, ecologia política e justiça ambiental: contribuições para uma análise crítica

O trabalho constrói uma conceituação dos chamados conflitos socioambientais, objetivando uma melhor compreensão destes enquanto objeto passível de ser estudado pela Geografia. Para que esse entendimento seja possível, lança-se mão de ferramentas analíticas oferecidas por duas perspectivas críticas: a ecologia política e a justiça ambiental. Demonstra que estes conflitos não são consequências espontâneas dos processos de exploração dos recursos naturais, mas produzidos a partir das diferentes formas de apropriação do meio que são mediadas pelas relações desiguais de poder.

Conflitos socioambientais pela mineração no Departamento de Antioquia - Colômbia O texto busca apreender a partir da compreensão de processos como a reprimarização 
da econômica latino-americana, as crises do sistema capitalista e a apropriação-privatização dos recursos naturais e do subsolo, um panorama dos efeitos e conflitos socioambientais em relação à mineração no departamento de Antioquia na Colômbia, visando compreender sua relação com as noções de desenvolvimento e modernização dos territórios e com a construção de movimentos sócio territoriais, lutas e resistências em defesa da vida, da água e do território.

Desenvolvimento sustentável para quem?

O trabalho considera a análise sobre a atuação de agências especializadas da Organização das Nações Unidas, notadamente no período posterior a crise do petróleo, importante para entender a imposição do discurso ideológico do desenvolvimento sustentável por meio de conferências internacionais e Think Tanks articulados em sistemas peritos globais que, assentado em prerrogativas de rearranjos técnicos, ampliam o desenvolvimento geográfico desigual colaborando com a territorialização de práticas espaciais neoliberais que se referem à exploração das condições sob as quais ocorre a dinâmica de práticas multifacetadas monopolistas, espacialmente articuladas, vinculadas com fluxos de capitais restritos.

Desterritorialização camponesa, reterritorialização quilombola: as territorialidades afro-brasileiras enquanto estratégias de resistência socioterritorial dos quilombos do Alagadiço, Minas Novas - Vale do Jequitinhonha-MG

Nesse trabalho foram abordados os processos de des-re-territorialização de grupos étnicos tradicionais do Vale do Jequitinhonha/MG a partir de reflexões sobre as estratégias de resistência criadas contra as invasões de seus territórios. O estudo foi realizado em três comunidades quilombolas do Município de Minas Novas: Quilombo, Santiago e São Pedro do Alagadiço, as quais vivenciaram, a partir da década de 1980, um trágico e perverso processo de compressão territorial. Constatou-se que o reconhecimento enquanto "comunidades quilombolas" representou um marco histórico para as suas famílias, pois foi por meio deste ato que elas foram reconhecidas como grupos culturalmente diferenciados e, assim, puderam construir estratégias de resistência que lhes permitiram permanecer num território que é, dialética e indissociavelmente, material e imaterial, espaço de reprodução socioeconômica e sociocultural.

Dos militares aos governos trabalhistas: discussões sobre "territórios instáveis" e a construção de um projeto de Estado brasileiro

A análise busca analisar desde o Brasil do século XX, as estratégias políticas e geopolíticas dos governos militares de 1964 e sua inserção internacional num quadro 
internacional adverso e o que se propunha enquanto governos trabalhistas, no caso do governo de Lula da Silva (2003) com uma nova postura do país nas relações internacionais e o fortalecimento das relações Sul-Sul e com os novos países chamados emergentes pelos organismos internacionais (FMI e BIRD).

Ilha da madeira (itaguaí-rj): o ringue da queda de braço entre o porto sudeste e os pescadores artesanais

A discussãotrazida buscou apresentar o conflito territorial que emerge diante da disputa de uso e apropriação do território da Ilha da Madeira, Município de Itaguaí (Rio de Janeiro). O conflito resulta da imposição de uma lógica privada, ditada pelo Porto Sudeste, sob o cotidiano de pescadores artesanais. Desta forma, busca-se traçar um panorama do conflito territorial, apresentando as estratégias do Porto Sudeste e dos pescadores artesanais.

O caráter interdisciplinar e o potencial transformador da agroecologia

A análise buscou mostrar que a agroecologia vem sendo debatida por vários pesquisadores, entre eles geógrafos, a partir de uma perspectiva contra-hegemônica no plano econômico, científico e social. Logo, buscou-se discutir o caráter interdisciplinar da Agroecologia e seu potencial transformador, seja no âmbito científico, ambiental e sociopolítico.

O conceito de território em transição: marcos epistemológicos de um debate na Geografia brasileira

O estudo buscou valorizar a forma com que o conceito de Território vem sendo analisado na Geografia brasileira considerando o contexto histórico de transição interpretativa que se define como pós-modernidade. Buscou-se demonstrar de que maneira a Geografia brasileira desenvolveu um percurso interpretativo sobre o território como conceito central da análise socioespacial. O estudo visa dispor um quadro de análise do debate territorial na epistemologia construída pela Geografia brasileira, buscando contextualizar historicamente o sentido do território (e das territorialidades) e suas múltiplas significações em um momento em que retorna com força sua centralidade mesmo diante dos processos de desterritorialização.

Uso do território, normas e política: dos "compartimentos quilombolas" ao bairro rural Negro Cafundó (Salto de Pirapora-SP)

Este estudo parte da discussão envolvendo a constituição do espaço e do território e os embates entre os "usos hegemônicos" e os "usos hegemonizados" deste último, a partir 
da aplicação do conceito de "territórios de legislação especial" às terras quilombolas e indígenas, tendo como finalidade analisar o processo de (re) conquista e uso do território pela comunidade rural negra do bairro Cafundó, no município de Salto de Pirapora-SP.

O papel decisivo dos royalties do petróleo na busca por emancipação do distrito de Barra de São João, em Casimiro de Abreu-RJ

Tal estudo mostra que ocorre no Brasil há anos uma intensa disputa pelo recebimento de receitas originárias do setor petrolífero, recursos que são vistos por diversos municípios como oportunidade de crescimento econômico. Nesse contexto, encontra-se Casimiro de Abreu, localizado no estado do Rio de Janeiro, que tem verificado nas últimas décadas crescente dependência em relação a esta fonte de arrecadação. O município está inserido na Zona de Produção Principal, em função da localização litorânea do distrito de Barra de São João. Emerge recentemente nesse distrito uma insatisfação popular, em função da prioridade dada pelo poder público aos investimentos no distrito sede, havendo a construção de um discurso emancipatório, tema a ser analisado nesta pesquisa.

O retorno dos brasiguaios e os conflitos identitários no espaço escolar

A pesquisa buscou compreender os conflitos identitários sofridos que envolvem os brasiguaios, buscando entender os conflitos agrários provocados pela presença de um outro grupo, os "brasileiros no Paraguai", que junto aos latifundiários paraguaios, realizam investidas sobre as terras dos pequenos e médios produtores agrícolas, tanto paraguaios, como de brasiguaios. Busca-se identificar a gênese destes conflitos identitários, problematizando possíveis situações de alteridades e poder que os brasileiros, ao se sentirem superiores em sua identidade cultural, estigmatizam os brasiguaios por serem provindos do Paraguai.

Poder, estado e capital nos processos des-reterritorialização no campo na microrregião geográfica de Campo Mourão-PR

O trabalho presenta uma discussão e reflexão sobre as relações de poder, o Estado e o capital nos processos de des-re-territorialização, no espaço rural da Microrregião Geográfica de Campo Mourão, Paraná, Brasil. A reflexão se estendeu ao processo de territorialização movido pela colonização, ao processo de desterritorialização movido pelo avanço das relações capitalistas no campo, e igualmente, sobre as novas e velhas territorialidades que surgem neste período. Em suma, estuda as territorialidades das cooperativas de produção agropecuária e de agricultura familiar, das agroindústrias, das associações de pequenos produtores rurais, de assentamentos e acampamentos vinculados ao Movimento dos 
Trabalhadores Rurais Sem Terra - MST, bem como das vilas rurais.

Políticas de exceção, racismo de Estado e o direito e acesso à documentação civil básica da população da reserva indígena de Dourados.

O texto problematiza a situação emblemática na qual se encontra a população indígena na Reserva Indígena de Dourados e a quais tipos de políticas estão submetidos, buscando, assim, através de novas práticas, desconstruir a realidade para construir novas políticas que de fato sejam efetivas e empoderadoras para esta população.

Políticas públicas de desenvolvimento territorial e suas dinâmicas no território da cidadania do alto Jequitinhonha (MG)

O trabalho identifica e problematiza as políticas públicas desenvolvidas pelo governo federal no Território da Cidadania do Alto Jequitinhonha, a partir do conceito de inovação social. Este conceito sistematiza uma resistência aos territórios do mercado ou do estado, por meio do qual foi possível concluir diversas dinâmicas estabelecidas de (re)existências no território a partir da ação do estado e do desenvolvimento territorial exercido pelos movimentos sociais, que juntos denotam e/ou reafirmam uma territorialidade de empoderamento e inclusão social, assim como atendimento às necessidades básicas em contrapondo a processos de mercado ou estado.

Resex Chico Mendes (AC) do projeto à realização: dos espaços de representação à representação do espaço

A abordagem trazida constata que a RESEX Chico Mendes no Acre é considerada uma conquista histórica para o movimento que desde a década de 1970 vinha resistindo contra a expropriação a partir do avanço da fronteira agropecuária na Amazônia. Como reivindicação popular estava uma outra lógica de reforma agrária, a qual a territorialidade e a (re)produção da família seringueira fosse contemplada. Porém, a institucionalização da RESEX se deu sob um Estado neoliberal e o processo de captura de um projeto sociopolítico fez com que os ideias dos seringueiros fossem se afastando em face a um projeto capitalista o qual a questão ambiental tornou-se uma estratégia de acumulação. Busca a compreensão sobre a constituição e concretização de um outro projeto, o qual não era o da demanda dos seringueiros.

Sinal vermelho: os territórios da população infanto juvenil nos semáforos da cidade de Campina Grande - PB

O texto discute a categoria território como categoria-chave da análise geográfica trazendo um levantamento epistemológico sobre o termo, e seus respectivos "derivados", 
territorialidades e territorialização. Analisa as construções/desconstruções dos territórios, nas mais variadas escalas e tempos, por crianças e adolescentes, nos principais semáforos da cidade de Campina Grande - PB.

Transformações do território cafeeiro e a configuração de um habitat urbano-rural no Departamento de Risaralda, Colômbia

A discussão apresentada retrata o contexto atual da atividade cafeeira em Risaralda/ Colômbia, fazendo uma abordagem sobre a chegada do café no país e no território estudado, contextualizandoas mudanças do sistema produtivo e a atuação de dois agentes: institucionalidade cafeeira e as organizações que trabalham paralelamente. Desta maneira, analiou-se a tensão entre estes dois agentes, levando em conta a sua participação na transformação da paisagem e portanto, a mesma vigência da declaratória emitida.

Considerando que o grupo de trabalho Geografia e poder: conflitos e resistências/ contra-poderes territoriais se propôs debater temas ligados à ciência geográfica em escala ampla, especialmente relacionados à Geografia Política, entre outras subáreas dessa ciência, é importante frisar que foram apresentados e discutidos conceitos e temas atinentes a questões ligadas a relações de poder diversas, forças políticas, econômicas e culturais numa abordagem multiescalar, problematizando-se as resistências territoriais de indivíduos e grupos sociais em várias regiões do Brasil e do mundo.

\section{REFERÊNCIAS}

1. BARRACHO, C. J. B. da S. Estratégias de poder e autoridade em contextos sócio-políticos diferenciados. Tese de Doutorado da Universidade de Santiago de Compostela. Santiago de Compostela: Espanha, 2007.

2. DAHL, R. A. The Concept of Power. Behavioral Science, 1957.

3. NOBRE, R. F.; BUENO, N. S. CAUX, C. de; LIMA, R. G. de \& LOPES, V. S. Poder no pensamento social. In: O poder no pensamento social: dissonâncias. Belo Horizonte: UFMG, 2008, p. 11-28.

4. PERISSINOTTO, R. M. Hannah Arendt, poder e a crítica da “tradição". Revista Lua Nova, n. 61, 2004. Disponível em <http://www.scielo.br/pdf/ln/n61/a07n61.pdf>.

5. PERISSINOTTO, R. M. Poder:imposição ou consenso ilusório? Por um retorno a Max Weber. In: O poder no pensamento social: dissonâncias. Belo Horizonte: UFMG, 2008, p. 29-58.

6. RAFFESTIN, C. Por uma geografia do poder. São Paulo: Ática, 1993.

7. SANCHEZ, J. E. La geografía y el espacio social del poder. Barcelona: Los Libros de la Frontera, 1981. 
8. ZACHARIAS, A.A. A representação gráfica das unidades de paisagem no zoneamento ambiental: um estudo de caso no município de Ourinhos-SP. Tese (Doutorado em Geografia), Instituto de Geociências e Ciências Exatas, Universidade Estadual Paulista, Rio Claro, 2006, 209 f.

Artigo recebido em 30 de junho de 2016.

Artigo aceito em 30 de julho de 2016. 